\title{
Adorno, Hanslick e a questão da autonomia estética da música
}

\author{
Adorno and Hanslick on the aesthetic autonomy of music
}

\author{
Mário Videira \\ Universidade de São Paulo, São Paulo, Brasil. \\ mario.videira@usp.br
}

Resumo: No semestre de inverno de 1932/33, Theodor Adorno ministrou na Universidade de Frankfurt um curso sobre o ensaio Do Belo Musical. Num artigo publicado alguns anos mais tarde, Adorno enfatizava a importância desse livro, uma vez que ele fixava o elemento da lógica imanente da composição musical, contra os autores que defendiam a música programática. Com efeito, um dos principais objetivos do ensaio de Hanslick era o estabelecimento da autonomia da obra musical. De acordo com ele, o belo na música é algo especificamente musical consistindo apenas e tão somente nos próprios sons e em sua combinação artística. Embora as referências diretas a Hanslick sejam relativamente raras e esparsas nos textos de Adorno, não devemos subestimar suas ressonâncias no pensamento desse autor. 0 objetivo desse artigo é investigar em que medida as ideias de Hanslick acerca da autonomia estética da música poderiam ter influenciado o conceito adorniano de material musical, bem como a sua abordagem da análise musical.

Palavras-chave:Theodor Adorno e Eduard Hanslick; o belo musical; autonomia estética da música.

Abstract: In the winter term 1932/33, Theodor Adorno conducted at Frankfurt University a seminar on Hanslick's essay Vom musikalisch-Schönen. In an article published some years later, Adorno emphasized the importance of this book, for it fixed the moment of immanent logic of musical composition against the authors that defended programmatic music. In fact, one of the main goals of Hanslick's essay is to discuss the establishment of a musical work autonomy. According to him, the beautiful in music is something specifically musical, consisting simply and solely of tones and their artistic combination. Despite direct references to Hanslick's ideas in Adorno's texts are somewhat rare and scattered, the resonances of the former in the thinking of the latter should be not underestimated. The purpose of this paper is to investigate to what extent Hanslick's ideas about the aesthetic autonomy of music might have influenced Adorno's concept of musical material as well as his approach to musical analysis.

Keywords: Theodor Adorno and Eduard Hanslick; Vom musikalisch-Schönen; aesthetic autonomy of music. 
VIDEIRA, Mário. (2016) Adorno, Hanslick e a questão da autonomia estética da música. Per Musi. Ed. por Fausto Borém e Lia Tomás. Belo Horizonte: UFMG, n.35, p.65-78.

Data de recebimento: $10 / 12 / 2015$

Data de aprovação final: 20/04/2016

\section{Introdução}

No semestre de inverno de 1932/33, Theodor Adorno ministrou na Universidade de Frankfurt um curso sobre o ensaio Do Belo Musical, de Eduard Hanslick. ${ }^{1}$ Num artigo publicado alguns anos mais tarde, Adorno enfatizava a importância desse livro, uma vez que ele fixava o elemento da lógica imanente da composição musical, contra os autores que defendiam a música programática. Com efeito, um dos principais objetivos do ensaio de Hanslick era o estabelecimento da autonomia da obra musical. De acordo com ele, o belo na música é algo especificamente musical: "uma beleza que, independente e não necessitada de um conteúdo trazido de fora", consistiria apenas e tão somente nos próprios sons e na sua combinação artística; um "fim em si mesmo, e de nenhum modo apenas meio ou material para a representação de sentimentos" (HANSLICK, 1994, p. 41-42).

Embora as referências diretas a Hanslick sejam relativamente raras e esparsas ${ }^{2}$, não devemos subestimar suas ressonâncias no pensamento de Adorno. 0 objetivo desse artigo é investigar em que medida as ideias de Hanslick acerca da autonomia estética

\footnotetext{
${ }^{1}$ Nos Gesammelte Schriften vol. 20.2 (Vermischte Schriften II: The Musical Climate for Fascism in Germany) lemos o seguinte relato de Adorno: "In the winter term 1932/33, immediately before Hitler took over, I had to conduct at Frankfurt University a seminar on Hanslick's treatise Vom musikalischSchönen, on the musically beautiful, which is essentially a defense of musical formalism against the doctrines of Wagner and the programmatic school" (ADORNO, 2003, p. 432).

${ }^{2}$ As passagens nos Gesammelte Schriften (GS) de Adorno, nas quais Hanslick é mencionado, são as seguintes: GS 13, p. 21, 207; GS 14, p. 344; GS 16, p. 667; GS 17, p. 238; GS 18, p. 62, 153; GS 19, p. 361; GS 20, p. 416, 432ss. e p. 749 .
} 
da música poderiam ter influenciado o conceito adorniano de material musical, bem como a sua abordagem da análise musical.

Na estética musical do início do século XIX, era geralmente defendido que o propósito definidor da música era o de suscitar os sentimentos dos ouvintes. ${ }^{3}$ Uma visão bastante comum era a que considerava que os sentimentos seriam o conteúdo da música. 0 belo musical era então considerado quase que exclusivamente pelo lado de sua impressão subjetiva, e se afirmava que os sentimentos constituíam o único fundamento estético da música. Era contra essas opiniões e contra a chamada "estética do sentimento" que o esteta e crítico musical Eduard Hanslick escreveu seu célebre ensaio Do Belo Musical, publicado pela primeira vez em 1854.

Neste livro, ele considerava que as investigações estéticas somente poderiam vir a bom termo rompendo com os métodos que consideravam o sentimento subjetivo como seu ponto de partida. De acordo com ele, o objeto primário da investigação estética deveria ser o objeto belo, e não os sentimentos do sujeito (HANSLICK, 1994, p. 14). Uma vez que o efeito da música sobre o sentimento não possui "nem a necessidade, nem a constância, nem a exclusividade" (HANSLICK, 1994, p. 20), que um fenômeno deveria apresentar para que se pudesse erigir num princípio estético, o autor considera que absolutamente nada é dito a respeito do princípio estético desta arte se a caracterizamos meramente de acordo com seu efeito sobre o sentimento. Ao invés disso, Hanslick acredita que é necessário penetrar no interior das obras musicais e, a partir dos princípios de sua própria estrutura, "a partir das leis do seu próprio organismo, explicar que conteúdo é o seu, em que consiste a sua beleza" (HANSLICK, 1994, p. 19). O autor afirma que cada arte particular deve ser conhecida

\footnotetext{
3"A música - assim nos ensinam - não pode entreter o entendimento por meio de conceitos, como a poesia, nem também o olho mediante formas visíveis, como as artes plásticas, portanto, terá a vocação de atuar sobre os sentimentos do homem" (HANSLICK, 1994, p. 14-15). No entanto, prossegue Hanslick (1994, p. 18-19), "confundem-se de modo incessante a afecção do sentimento e a beleza musical". Cf. também HANSLICK (1994, p. 23-24).
} 
"nas suas determinações técnicas, [...] compreendida e julgada a partir de si própria" (HANSLICK, 1994, p. 14).

Hanslick (1994, p. 25) argumenta que a música não tem nenhum propósito para além de si mesma: as ideias que um compositor produz são, antes de mais nada, ideias puramente musicais e elas devem existir pelo único propósito de serem elas mesmas. Após rejeitar a teoria dos sentimentos como inadequada, o autor defende um princípio completamente autônomo para o belo musical. Em suas palavras:

\begin{abstract}
Até agora, abordamos as obras de um modo negativo e tentamos simplesmente rejeitar o pressuposto errôneo de que o belo musical poderia consistir na representação de sentimentos. Devemos agora acrescentar o conteúdo positivo desse perfil ao respondermos a questão relativa à natureza do belo na arte sonora. É algo de especificamente musical. Entendemos por ele uma beleza que, independente e não necessitada de um conteúdo trazido de fora, radica unicamente nos sons e na sua combinação artística. As relações significativas de sons, [...] a sua harmonia e contraposição, o seu fugir e seu alcançar-se, o seu elevar-se e o seu apagar-se - eis o que se apresenta à nossa intuição espiritual em formas livres e o que nos agrada como belo. [...] Se se perguntar o que se há de expressar com este material sonoro, a resposta é: ideias musicais [musikalische Ideen]. Mas uma ideia musical trazida inteiramente à manifestação é já um belo autônomo, é fim em si mesmo [Selbstzweck], e de nenhum modo apenas meio ou material para a representação de sentimentos e pensamentos (HANSLICK, 1994, p. 41-42).
\end{abstract}

Ao invés da representação de sentimentos, Hanslick (1994, p. 42) considera que o único e exclusivo conteúdo e objeto da música são as "formas sonoras em movimento". Esta formulação aparentemente paradoxal ressalta a impossibilidade de se separar forma e conteúdo no caso da música. "Na música”, escreve Hanslick (1994, p. 103), "vemos o conteúdo e a forma [...] confundidos numa unidade obscura e indivisível" e, no caso da música, "não existe conteúdo oposto à forma", justamente porque a música não possui forma que possa ser separada de seu conteúdo. ${ }^{4} \mathrm{As}$ formas sonoras que constituem a música não possuem outro conteúdo além de si mesmas, e seu conteúdo nada mais é que as formas sonoras audíveis: "A música

4É interessante notar que Adorno (1989, p. 42) irá defender um ponto de vista semelhante em sua Filosofia da Nova Música, ao afirmar: "Pode-se forjar uma ideia da compenetração de forma e conteúdo em toda a música. É insensato, portanto, pretender condenar como formalista uma articulação técnica tão ampla". 
consta de séries de sons, de formas sonoras que não têm nenhum outro conteúdo além de si mesmas. [...] 0 conteúdo nada mais é do que precisamente as formas sonoras ouvidas, pois a música não se manifesta só por meio de sons, mas expressa apenas sons" (HANSLICK, 1994, p. 100). Assim, fica claro que o conteúdo da música é um conteúdo puramente musical, derivado de sua estrutura sonora.

Hanslick critica severamente a concepção tradicional de música como linguagem dos sentimentos ou como linguagem imediata do coração. De acordo com ele, "a música possui lógica e sentido - porém musicais. É uma linguagem que falamos e entendemos, mas que não somos capazes de traduzir" (HANSLICK, 1994, p. 44). Relativamente ao relacionamento entre música e a linguagem das palavras, ele também defende a radical autonomia e independência do belo na música. Enquanto na linguagem verbal o som é apenas um signo, ou seja, "um meio para um fim que é inteiramente distinto daquilo que ela significa", na música o som aparece para nós como um fim em si mesmo (HANSLICK, 1994, p. 42). Todas essas ideias têm consequências importantes para a atividade do compositor, do ouvinte e do intérprete.

No que diz respeito à composição musical, torna-se claro que o compositor deve dar forma a uma obra dotada de um belo autônomo: as ideias expressas numa peça musical não são conceituais, mas sim, ideias musicais. Por este motivo, as leis da construção de uma peça musical devem estar fundamentadas exclusivamente em suas determinações musicais, ou seja, em seu material musical, em sua lógica e coerência internas. ${ }^{5}$ De acordo com Hanslick (1994, p. 51), "assim como o belo de uma peça musical radica simplesmente nas suas determinações musicais, assim também obedecem apenas a estas as leis de sua construção". A peça musical deve estar apta a agradar em si mesma, "como o arabesco, a coluna ornamental, ou como produtos do belo natural, tais como folhas e flores" (HANSLICK, 1994, p. 45).

\footnotetext{
5“O compositor não pensa na representação de um conteúdo determinado. Se o fizer, põe-se num ponto de vista equivocado, mais ao lado do que no interior da música. A sua composição torna-se então a tradução de um programa em sons, que sem tal programa ficam incompreensíveis" (HANSLICK, 1994, p. 49).
} 
No que diz respeito ao ouvinte, a principal consequência é a necessidade de que a contemplação estética não possa estar baseada em nenhuma característica que esteja fora das próprias obras de arte: trata-se de uma contemplação pura e consciente da obra musical (HANSLICK, 1994, p. 82). De acordo com Hanslick, “a música pretende ser apreendida como música" e pode apenas ser compreendida a partir de si mesma e fruída em si mesma. Entretanto, o belo especificamente musical não deve ser compreendido como mera beleza acústica ou como simetria das proporções, e ainda menos podemos falar de um "jogo de sons que faz cócegas no ouvido" e outras imagens desse tipo (HANSLICK, 1994, p. 43).

O fato de que grande número de pessoas ouve música numa receptividade meramente passiva, deixando que os seus sentimentos predominem nessa audição, é caracterizado por Hanslick como uma espécie de "atitude patológica" em relação à peça musical: “Aninhados e semidespertos no seu sofá, aqueles entusiastas deixam-se levar e embalar pelas vibrações dos sons", ao invés de os examinarem com atenção (HANSLICK, 1994, p. 76).

A contemplação estética da música, pelo contrário, pressupõe um tipo de atividade mental do ouvinte, uma contemplação livre de um belo especificamente musical. Ao invés de ouvir música de um modo meramente passivo, buscando um prazer apenas no aspecto meramente sensível dos sons, a obra musical exige dos ouvintes um acompanhamento incansável e com a mais intensa concentração, que pode, no caso de composições complexas e intrincadas, "elevar-se ao nível de um trabalho intelectual" (HANSLICK, 1994, p. 83).

"O conteúdo espiritual de uma composição", segundo Hanslick, está nas estruturas sonoras concretas, e não "na vaga impressão geral de um sentimento abstrato". A própria forma, isto é, a configuração sonora, é o verdadeiro conteúdo da música; ao passo que o sentimento suscitado "não pode chamar-se nem conteúdo, nem forma, mas efeito fáctico" (HANSLICK, 1994, p. 77). De acordo com Hanslick (1994, p. 85), o requisito mais indispensável para que possamos ouvir música esteticamente é que a ouçamos em si mesma, sem referência a nenhum conteúdo externo. Assim que uma 
determinada música é usada "meramente como meio para fomentar em nós uma certa disposição de ânimo, de modo acessório e decorativo, cessa de atuar como arte". Após esta breve exposição de alguns dos principais aspectos do pensamento musical de Hanslick, gostaria de explorar possíveis ressonâncias de suas ideias em alguns textos escritos por Adorno.

\section{II}

Certamente não é exagerado afirmar que o desenvolvimento da estética musical durante o século XX foi influenciado, em muitos pontos cruciais, pelas ideias de Hanslick a respeito da autonomia estética da música. Isto se torna bastante claro quando examinamos alguns textos escritos pelos principais compositores da Segunda Escola de Viena. Num artigo publicado originalmente em 1920, o compositor austríaco Alban Berg - que, aliás, foi professor de Adorno - escreveu: "Deve haver alguma possibilidade de dizer algo irrefutável acerca da beleza de uma melodia, algo que fará dela algo acessível ao entendimento e despertará um senso de sua qualidade. Naturalmente, algo de natureza musical, e não referente ao sentimento e entusiasmo demasiadamente pessoal" (BERG, 1974, p. 209). Outro exemplo semelhante pode ser encontrado no livro de Anton Webern "O caminho para a nova música", especialmente quando ele coloca a seguinte questão:

\footnotetext{
Como as pessoas ouvem música? Como a ouve a grande massa? Aparentemente ela precisa se orientar por certas imagens ou "estados de espírito". Sente-se perdida quando não pode imaginar um prado verde, um céu azul ou algo do gênero. Escutando-me agora, vocês acompanham um desenvolvimento lógico de ideias. No entanto, não é assim que tais pessoas acompanham os sons musicais (WEBERN, 1984, p. 33).
}

Da mesma forma, em sua Teoria Estética, Adorno enfatiza o fato de que o "sentimento estético não é aquilo que é suscitado em nós". Pelo contrário, de acordo com Adorno, "o efeito subjetivo suscitado pela arte é a última coisa que gostaríamos de dignificar com o nome de sentimento estético. 0 verdadeiro sentimento estético é orientado 
pelo objeto; é o sentimento do objeto, e não algum reflexo naquele que contempla" (ADORNO, 1984, p. 236).

No caso de uma obra musical, as características mais importantes para Adorno são: a arte da manipulação temática, a estrita economia motívica e a consistência imanente [Stimmigkeit] da composição. Numa carta ao compositor Ernst Krenek, Adorno escreveu que "é apenas em sua consistência imanente que uma obra se prova como progressiva". Ele continua: "Em cada obra, o material registra demandas concretas, e o movimento com o qual cada nova obra manifesta essas demandas é a única figura [Gestalt] obrigatória da história para o autor. Uma obra que atenda completamente a essas demandas é consistente [stimmig]" (ADORNO apud PADDISON, 1993, p. 89). A compreensão de uma composição não pode se dar por meio da investigação das intenções subjetivas do compositor, mas apenas mediante a análise crítica da obra de arte musical, a fim de reconhecer como o compositor lidou com as demandas concretas do material musical, que consequências ele derivou dos problemas existentes no material e como ele organizou o todo de acordo com esses princípios. Em seu livro sobre Alban Berg, Adorno afirma que uma reconstrução convincente daquilo que o próprio compositor tinha em mente é não apenas algo praticamente impossível, como também, em grande medida, irrelevante:

\footnotetext{
Em arte, tudo depende do produto, do qual o artista é o instrumento [Organ]. Dificilmente poder-se-ia reconstruir de maneira conclusiva o que o próprio artista tinha em mente; mas isso é também, em larga medida, irrelevante. Em virtude de sua legalidade imanente, a obra impõe suas características àquele que a realiza, ao seu autor, sem que ele tenha de refletir especificamente a respeito disso. Quanto mais completamente o artista se abandonar ao seu tema, tanto melhor será a obra. Sua submissão às exigências que se lhe apresentam desde o primeiro compasso pesa infinitamente mais do que a intenção do artista (ADORNO, 2010, p. 97).
}

Este ponto de vista acarreta algumas consequências importantes tanto para o intérprete como para o ouvinte. Adorno (1989, p. 20) insiste que a audição de uma obra de arte musical não deveria ser uma mera "percepção passiva do som físico" ou algo comparável a uma fruição "culinária" da música. Ele condena a "escuta atomística", que se perde passivamente no encanto do som isolado. Para Adorno 
(2002, p. 318), esse tipo de escuta pertence ao âmbito pré-artístico: "uma vez que a música carece de conceitos, a pessoa que a ouve atomisticamente não é capaz de percebê-la como algo intelectual e espiritual [Geistiges]". Num texto intitulado "Para uma compreensão de Schoenberg", ele escreve:

0 hábito auditivo dominante, e que talvez esteja crescendo de maneira ainda mais forte graças à indústria cultural, o negócio da música que é total e completo entretenimento, está calibrado para que se perceba a música de maneira mais ou menos desconcentrada, como uma sequência de estímulos sensíveis isolados. Há razão para crer que mesmo a assim chamada música clássica é, em grande medida, consumida desta maneira (ADORNO, 2002, p. 632).

No entanto, o ensinamento de Schoenberg (apud ADORNO, 1989, p. 41), segundo o qual "a música não deve enfeitar, mas deve ser verdadeira" é levado a sério por Adorno, uma vez que, para o filósofo, a única forma de apreender o "conteúdo de verdade" [Wahrheitsgehalt] de uma obra musical é através da análise e "escuta estrutural" da música. Ainda a respeito desse tipo de escuta estrutural, Adorno escreve em sua "Introdução à sociologia da música":

\footnotetext{
O próprio expert [...] deveria ser definido segundo o critério de uma escuta totalmente adequada. Ele seria o ouvinte plenamente consciente, ao qual, a princípio, nada escapa e que, ao mesmo tempo, presta contas daquilo que escuta. [...] Ao seguir espontaneamente o curso de uma música intrincada, ele escuta a sequência de instantes passados, presentes e futuros de modo tão contíguo que uma interconexão de sentido se cristaliza. Ele apreende até mesmo os elementos intrincados da simultaneidade, como a harmonia e a polifonia. 0 comportamento adequado poderia ser caracterizado como escuta estrutural. Seu horizonte é a lógica musical concreta: compreende-se aquilo que se apreende em sua necessidade, que decerto nunca é literalmente causal. O lugar dessa lógica é a técnica; para aquele que também pensa com o ouvido, os elementos individuais da escuta se tornam imediatamente atuantes como elementos técnicos, sendo que nas categorias técnicas se revela, essencialmente, a interconexão de sentido (ADORNO, 2011, p. 60-61, grifos nossos).
}

De acordo com Max Paddison (2002, p. 210) tal ênfase na "escuta estrutural" indica, ao mesmo tempo, a centralidade da análise musical para o pensamento de Adorno, o qual "considera as obras de arte autônomas como possuidoras de múltiplas camadas e sendo objetivamente estruturadas em si mesmas, com suas próprias demandas às quais o ouvinte deve responder/reagir". 
Para Adorno (2002, p. 173), a tarefa da análise é revelar tão claramente quanto possível o problema de cada obra em particular: portanto, a análise se preocupa com estruturas, isto é, com problemas estruturais e, por fim, com a escuta estrutural. "Por estrutura", escreve Adorno, "não me refiro [...] ao mero agrupamento das partes da música, de acordo com os esquemas formais tradicionais, pelo contrário: entendo-a, antes, em relação com o que acontece musicalmente, por baixo desses esquemas formais" (ADORNO, 2002, p. 164). Para que o "conteúdo de verdade" [Wahrheitsgehalt] de uma obra seja revelado, Adorno (2002, p. 167) considera que é necessária à sua análise. Portanto, fica claro que uma tal concepção de análise é também o pré-requisito para uma interpretação adequada, pois se o intérprete não conhece intimamente a obra, ele não estará apto a interpretá-la de maneira apropriada: “'Conhecer algo intimamente' [...] significa, na realidade, 'analisar', isto é, investigar as relações internas da obra e investigar o que está essencialmente contido na composição" (ADORNO, 2002, p. 163).

Adorno considera que a análise possui importância fundamental não apenas para a interpretação de uma obra musical, mas também para a formulação das teorias estéticas sobre a música: ele afirma que todos os julgamentos feitos acerca da música são inconcebíveis sem a análise. Portanto, toda crítica que pretenda ter algum valor, deve estar fundamentada na análise, pois do contrário, "a crítica permanece presa a impressões desconexas e, por este motivo, [...] merece ser vista com a máxima suspeita" (ADORNO, 2002, p. 168).

Como se vê, não é apenas o papel do compositor, mas também o do ouvinte, do intérprete e do crítico musical que se mostram marcados profundamente pela ideia de autonomia estética da música. É com razão que o musicólogo Max Paddison (2004, p. 206) observa que "isso tudo deve ser compreendido no contexto da noção de uma obra de arte completamente autônoma na música ocidental [...] historicamente liberada de suas origens funcionais". 


\section{III}

Para Max Paddison (2004, p. 206), não apenas a ideia de uma autonomia estética da música, mas também o conceito adorniano de material musical como a "objetificação do sujeito" e como "espiritualização da matéria", remontam à ideia hanslickiana da composição como o trabalho do espírito em material apto ao espírito. Paddison (2004, p. 76) considera ainda que as concepções de música e de material musical como a "matéria bruta" permeada pelo "espírito", também seriam reminiscentes da estética de Hanslick.

Um outro ponto da filosofia da música de Adorno que certamente poderia remeter a Hanslick é a ideia de que a música diz algo que somente pode ser dito através da própria música (ADORNO, 2002, p. 138). Apesar das similaridades entre música e linguagem, Adorno enfatiza o fato de que a música não forma um sistema de signos. Por esta razão, a música fornece o protótipo da intraduzibilidade. A música possui um caráter enigmático, o qual é enfatizado pelo seu distanciamento do mundo da visualidade ou do mundo de objetos conceitualmente determinados (ADORNO, 2002, p. 138). De acordo com Adorno (2002, p. 122), a música não pode ser fixada de modo a tentar saber o que ela fala, "e contudo ela fala". Talvez mais do que todas as demais formas de arte, o que é dito através da música não pode ser abstraído da própria música. A identidade dos conceitos musicais não reside em algo aos quais estes se referem. Pelo contrário, reside em sua própria existência:

\footnotetext{
A música, em relação à linguagem intencional, mostra-se de um tipo completamente diferente [...] A música aponta para uma linguagem desprovida de intenção. Porém, ela não se separa definitivamente do intencional como reinos distintos. Impera aí uma dialética: ela está disseminada de intenção por todas as partes. [...] Música sem qualquer intenção, a mera conexão fenomênica dos sons, pareceria um caleidoscópio acústico. Por outro lado, como intenção absoluta, ela cessaria de ser música, e se converteria falsamente em linguagem (ADORNO, 2008, p. 168-69).
}

Apesar de todos esses pontos de contato com as ideias de Hanslick, Adorno também faz algumas objeções ao crítico vienense. Ele considera, por exemplo, que o prazer 
estético suscitado pelas "formas sonoras em movimento" seria um princípio demasiado tênue e abstrato para servir como fundamento para uma forma artística altamente organizada como é o caso da música. Se assim fosse, "então não haveria nenhuma diferença entre um caleidoscópio e um quarteto de Beethoven, exceto a diferença no material" (ADORNO, 2002, p. 139). 0 filósofo considera ainda que a tese de Hanslick - segundo o qual a música consistiria somente de formas sonoras em movimento - resume-se "a um estímulo vazio ou à mera existência de algo que reverbera" (ADORNO, 2002, p. 116).

Embora seja crítico a Hanslick quanto a esse aspecto, cabe notar que Adorno tampouco aceita a tese oposta, defendida pela assim chamada "estética da expressão", pois ele considera que "o elemento da expressão, no qual as pessoas perceberam o corretivo ao princípio de Hanslick citado acima, é demasiado ambíguo em cada instância isolada, e demasiado vago para representar o conteúdo da música por si mesmo" (ADORNO, 2002, p. 139). Assim, de acordo com Adorno (2002, p. 116), o erro da estética da expressão estaria no fato de confundir "as intenções individuais, ambiguamente fugitivas, pelo conteúdo desprovido de intenção do todo". Além disso, para Adorno (2002, p. 117), a estética da expressão, "onde ela é consistente, termina com o ato tentadoramente arbitrário de substituir o que foi entendido de maneira efêmera e acidental, pela objetividade da coisa mesma". Desta forma, tanto a estética da forma como a estética da expressão seriam insuficientes para apreender a complexidade da música:

\footnotetext{
Assim como a música não se esgota em intenções, por outro lado, contudo, não existe música que seja desprovida de elementos expressivos: em música, até mesmo a falta de expressividade se transforma em expressão. "Sonoro" e "em movimento" são praticamente a mesma coisa no caso da música, e o conceito de "forma" nada explica acerca do que foi ocultado, mas tão somente afasta a questão sobre o que é representado no contexto dos sons em movimento, que é mais do que a mera forma. A forma é somente forma de algo que foi formado. A necessidade específica, a lógica imanente daquele ato escapa à compreensão: ela [a forma] se torna um mero jogo, no qual literalmente tudo poderia ser de outra maneira. [...] A música não é redutível nem ao mero ser-em-si de seu som, nem ao mero ser-para-o-sujeito. A música é um meio de cognição que é velado tanto para si mesma quanto para o sujeito cognoscente. Mas pelo menos isto ela possui em comum com a forma
} 
discursiva do conhecimento: ela não pode ser completamente resolvida seja na direção do sujeito, seja na direção do objeto, e cada um destes é mediado pelo outro. (ADORNO, 2002, p. 117).

\section{Conclusão}

Não obstante haja uma recorrência de muitos temas da estética musical de Eduard Hanslick nos textos adornianos sobre música, esta não pode ser reduzida a uma mera "influência". Pelo contrário, há aqui uma relação complexa entre ambos autores, a qual certamente merece uma investigação mais aprofundada. Uma vez que o manuscrito do curso dado por Adorno (1932/33) a respeito do ensaio de Hanslick parece ter desaparecido ${ }^{6}$, seria necessário consultar outras fontes (tais como os cadernos de notas de seus alunos) e proceder a um estudo mais detalhado de todas as referências a Hanslick nos textos de Adorno, a fim de tentar reconstituir, mesmo que de uma maneira indireta, a figura de Adorno como leitor de Hanslick. Esta pesquisa ainda está por ser feita. Mas os resultados parciais sugerem que a relação entre ambos autores não é nem de epigonismo, nem de simples continuidade. Nos textos de Adorno não há nem uma completa assimilação, nem uma total rejeição das teorias de Hanslick, mas antes, delicados pontos de contato entre ambas concepções da arte da música.

\section{Referências}

1. ADORNO, Theodor W. (1984). Aesthetic Theory. Transl. by C. Lenhardt. London: Routledge.

2. ___ (2010). Berg: o mestre da transição mínima.Trad. M. Videira. São Paulo: Ed. Unesp.

3. ___ (2002). Essays on music. Commentary and notes by. R. Leppert. Transl. by S. Gillespie. Los Angeles: University of California Press.

\footnotetext{
${ }^{6}$ De acordo com informação fornecida por Michael Schwarz (Akademie der Künste Archiv, Berlin), em correspondência de 11 de março de 2008: "Leider haben sich im Nachlaß Adornos keine Aufzeichnungen über das Seminar erhalten, in dem er die Schrift Vom musikalisch-Schönen behandelt hat".
} 
4. . (1989). Filosofia da Nova Música. 2. ed. Trad. M. França. São Paulo: Perspectiva.

5. . (2008). Fragmento sobre música e linguagem. Trad. M. D. Barros. Trans/Form/Ação. São Paulo, 31 (2), p. 167-171.

6. . (2011). Introdução à Sociologia da Música: doze preleções teóricas.

Trad. F. R. Moraes Barros. São Paulo: Ed. Unesp.

$7 . ـ$ _ (2003).Vermischte Schriften I/II. In Gesammelte Schriften 20.1/2.Hrsg. R. Tiedemann. Frankfurt a. M.: Suhrkamp Verlag.

8. BERG, Alban. (1974). “The Musical Impotence of Hans Pfitzner's 'New Aesthetic”'. In: Reich, Willi. Alban Berg. Transl. C. Cardew. N. York: Vienna House.

9. HANSLICK, Eduard. (1994). Do Belo Musical. Trad. Artur Morão. Lisboa: Ed. 70.

10. PADDISON, Max. (1993). Adorno's Aesthetics of Music. Cambridge: Cambridge University Press.

11.___ (2004). "Authenticity and Failure in Adorno's Aesthetics". In: Cambridge Companion to Adorno, Ed. por Tom Huhn. Cambridge: Cambridge University Press.

12.___ (2002). "Immanent Critique or Musical Stocktaking? Adorno and the Problem of Musical Analysis”. In: GIBSON, Nigel. C.; RUBIN, Andrew (eds.)

Adorno: a critical reader. Oxford: Blackwell.

13. WEBERN, Anton. (1984). 0 caminho para a música nova. 2. ed. Trad. C. Kater. São Paulo: Novas Metas.

Notas sobre o autor

Mario Videira, possui graduação em Música (2001) e em Filosofia (2008) pela Universidade de São Paulo, mestrado em Musicologia pela Universidade Estadual Paulista-Unesp (2004), sob orientação da Profa. Dra. Lia Tomás. É doutor em Filosofia (2009) pela Universidade de São Paulo-USP, sob orientação do Prof. Dr. Marco Aurélio Werle. Publicou o livro O Romantismo e o Belo Musical (2006), pela Editora Unesp, além de diversos artigos em revistas especializadas. Como bolsista CNPq/DAAD realizou estágio de pesquisa (doutorado-sanduíche) na Eberhard-Karls Universität Tübingen, sob orientação do Prof. Dr. Manfred Frank (2006-2008). Publicou a primeira tradução em língua portuguesa do livro Berg: Mestre da Transição Mínima, do filósofo alemão Theodor W. Adorno (Ed. Unesp). É Coordenador do Programa de Pós-Graduação em Música da ECA/USP, vice-presidente da Comissão de Pós-Graduação da ECA/USP e editor-responsável da Revista Música (PPGMUS/ECA/USP). 